\title{
Enhanced extracellular expression of Bacillus stearothermophilus a-amylase in Bacillus subtilis through signal peptide optimization, chaperone overexpression and a-amylase mutant selection
}

\author{
Dongbang Yao ${ }^{1,2,3}$, Lingqia Su ${ }^{1,2,3}, \mathrm{Na} \mathrm{Li}^{1,2,3}$ and Jing $\mathrm{Wu}^{1,2,3^{*}}$ (i)
}

\begin{abstract}
Background: Our laboratory has constructed a Bacillus stearothermophilus a-amylase (AmyS) derivative with excellent enzymatic properties. Bacillus subtilis is generally regarded as safe and has excellent protein secretory capability, but heterologous extracellular production level of B. stearothermophilus a-amylase in B. subtilis is very low.
\end{abstract}

Results: In this study, the extracellular production level of B. stearothermophilus a-amylase in B. subtilis was enhanced by signal peptide optimization, chaperone overexpression and a-amylase mutant selection. The a-amylase optimal signal peptide $\left(\mathrm{SP}_{\text {YojL }}\right.$ ) was obtained by screening 173 B. subtilis signal peptides. Although the extracellular a-amylase activity that was produced by the resulting recombinant strain was 3.5-fold greater than that of the control, significant quantities of inclusion bodies were detected. Overexpressing intracellular molecular chaperones significantly reduced inclusion body formation and further increased a-amylase activity. Error-prone PCR produced an amylase mutant K82E/S405R (AmySA) with enzymatic activity superior to that of AmyS. Expression of the amySA gene with the SP YojL while overexpressing molecular chaperones resulted in a 7.1-fold improvement in a-amylase activity. When the final expression strain (WHS11YSA) was cultivated in a 3-L fermenter for $92 \mathrm{~h}$, the a-amylase activity of the culture supernatant was $9201.1 \mathrm{U} \mathrm{mL}^{-1}$, which is the highest level that has been reported to date.

Conclusions: This is the first report that describes an improvement of B. stearothermophilus a-amylase extracellular production levels in B. subtilis using these strategies, and this represents the highest extracellular production level ever reported for a-amylase from B. stearothermophilus in B. subtilis. This high-level production provides a basis for enhanced industrial production of a-amylase. These extracellular production level improvement approaches are also expected to be valuable in the expression of other enzymes in B. subtilis.

Keywords: Alpha-amylase, Signal peptide, Chaperone, Mutant, High-cell-density fermentation

\section{Background}

Alpha-amylases (EC 3.2.1.1), which catalyse the hydrolysis of 1,4-glycosidic bonds in starch and related carbohydrates to produce substances with low degrees of polymerization such as glucose, maltodextrin, and oligosaccharides, are widely used in the food, pharmaceutical,

\footnotetext{
*Correspondence: jingwu@jiangnan.edu.cn

${ }^{1}$ State Key Laboratory of Food Science and Technology, Jiangnan

University, 1800 Lihu Avenue, Wuxi 214122, Jiangsu, China

Full list of author information is available at the end of the article
}

detergent, and textile industries [1]. Alpha-amylases can be isolated from a wide range of sources. Those from microbial sources have received increasing attention due to their low production costs, good fermentation stability, and short production time [2]. The $\alpha$-amylases from Bacillus species are the most widely used, with those from B. subtilis, B. licheniformis, B. amyloliquefaciens and $B$. stearothermophilus having important industrial applications [3].

With the development of DNA recombination technology, the heterologous expression of $\alpha$-amylases from 
different sources has been widely studied. Heterologous expression of the $\alpha$-amylases from $B$. licheniformis, $B$. amyloliquefaciens and $B$. stearothermophilus have been reported in Escherichia coli, B. licheniformis, B. subtilis, and other hosts [4-6]. B. subtilis, a Gram-positive bacterium, offers several advantages. Because $B$. subtilis is classified "generally recognized as safe" (GRAS), it can be used when food safety issues are important. In addition, its genetic manipulation is relatively simple and the product is directly secreted into the extracellular medium. For these reasons, B. subtilis has been used to produce a variety of heterologous proteins and chemicals. However, heterologous expression of $\alpha$-amylases from different microbial sources in $B$. subtilis results in very different extracellular production levels. The extracellular $\alpha$-amylase activities reported for the $\alpha$-amylases from $B$. licheniformis, B. stearothermophilus, $B$. amyloliquefaciens and Thermococcus sp. HJ21 expression in B. subtilis are $2012 \mathrm{U} \mathrm{mL}^{-1}$ [7], $5086 \mathrm{U} \mathrm{mL}^{-1}$ [8], $14 \mu \mathrm{g} \mathrm{mL}{ }^{-1}$ [9], and $19.6 \mathrm{U} \mathrm{mL}^{-1}$ [10], respectively.

Efforts to improve the level of heterologous protein expression in B. subtilis have included optimization of the signal peptide, transport channel level, chaperone protein level, promoter and other factors of the expression and transport systems. The signal peptide, a special amino acid sequence located at the $\mathrm{N}$-terminus of the secreted protein, plays an important role in protein transport. It helps keep the protein precursor in a transportable folding state, targets the protein precursor to the appropriate transport machinery, and assists transmembrane secretion of the protein into the extracellular medium [11]. Brockmeier et al. [12] pointed out that establishing a library of $B$. subtilis signal peptides and using it to screen for the optimal signal peptide for each foreign protein is an important means to improve heterologous extracellular production levels in $B$. subtilis. They used this method to increase extracellular cutinase activity to $4.7 \mathrm{U} \mathrm{mL}^{-1}$. Similarly, Zhang et al. [13] screened 114 signal peptides from the Sec-dependent secretion pathway of B. subtilis to identify the optimal signal peptide $\left(\mathrm{SP}_{\mathrm{PhoB}}\right)$ for heterologous xylanase expression in B. subtilis. Using this technique, they increased the extracellular xylanase activity to $193.7 \mathrm{U} \mathrm{mL}^{-1}$. In addition, Tsuji et al. [14] screened $173 \mathrm{~B}$. subtilis signal peptides to identify the best signal peptide $\left(\mathrm{SP}_{\mathrm{Pbp}}\right)$ for heterologous natto phytase expression in B. subtilis. The resulting recombinant strain, TSU004, produced twice the natto phytase activity obtained using the control strain TSU003.

Naturally, successful secretion of recombinant proteins from $B$. subtilis requires that intracellular chaperones prevent inappropriate folding or aggregation of the protein precursors within the cell and that the intracellular protein precursors undergo efficient transmembrane transport. There are two types of intracellular chaperones in B. subtilis [15]. One type targets protein precursors to membrane transport channels in the cell. Examples of this type include Ffh and FtsY. The other type keeps the protein precursor folded in a state that can be secreted across the membrane. Examples of this type include trigger factor (TF), GroEL, GroES, DnaK, DnaJ, and GrpE. Chen et al. [6] increased the extracellular activity of AmyL by $132 \%, 133 \%$ and $138 \%$, compared with a control, by overexpressing ftsy, a partial $d n a K$ operon, and $S R P$, respectively, in B. subtilis. They also increased extracellular AmyS activity to $124 \%, 125 \%, 126 \%$ and $149 \%$, compared with a control, by overexpressing SRP, ftsy, the groESL operon, and a partial dnaK operon, respectively, in B. subtilis.

The $\alpha$-amylase from $B$. stearothermophilus has received increasing attention due to its high specific activity and acid resistance [16]. Although B. stearothermophilus can secrete amylase naturally, the natural extracellular production of amylase produced by $B$. stearothermophilus is relatively low [17]. Therefore, recombinant expression of the amylase is necessary to increase its production [17]. However, B. stearothermophilus is not a commonly used expression host strain, its genetic background is not yet clear, and the corresponding molecular manipulation techniques are not yet mature. In addition, the culture temperature of amylase produced by B. stearothermophilus is relatively high at approximately $55^{\circ} \mathrm{C}$, which is not conducive to the industrial production of amylase [18]. In contrast, the B. subtilis expression system is established, the genetic background is clear, and the corresponding molecular manipulation techniques are relatively mature. Therefore, in this study, the B. stearothermophilus amylase was heterologously expressed in $B$. subtilis. In previous studies, heterologous expression of $B$. stearothermophilus $\alpha$-amylase in $B$. subtilis produced low levels of enzyme activity. Although the overexpression of molecular chaperones, signal peptide optimization and other efforts have increased extracellular production levels, the highest amylase activity in the fermentation supernatant reported to date is only $5086 \mathrm{U} \mathrm{mL}^{-1}$ [8]. Because B. stearothermophilus amylase has important application value for maltooligosaccharide and high fructose syrup production, and the amylase industrial demand is large, increasing its production is very important to decrease the application cost. Although there are other avenues of research that could prove useful, few related literature reports. For example, few reports describe mutation of the target protein to increase enzyme activity as a way to increase the level of heterologous expression of $B$. stearothermophilus $\alpha$-amylase in $B$. subtilis. In this study, we combined a signal peptide screening campaign, an intracellular chaperone 
overexpression strategy, and a random mutagenesis strategy to improve heterologous expression of B. stearothermophilus $\alpha$-amylase in $B$. subtilis. Once an optimal expression strain was constructed, its ability to produce $B$. stearothermophilus $\alpha$-amylase was verified using a $3-\mathrm{L}$ fermenter.

\section{Materials and methods}

Bacterial strains and media

All strains used in this study are listed in Table 1. E. coli JM109 was used to construct recombinant vectors. $E$. coli BL21 was used to screen for $\alpha$-amylase mutants with improved $\alpha$-amylase activity. B. subtilis RIK1285 was used to screen signal peptides in $\alpha$-amylase production. B. subtilis WS11 and WHS11 were used as heterologous expression hosts for $\alpha$-amylase. The $\alpha$-amylase gene (amyS) from B. stearothermophilus was used in this study. The LB medium was used as the seed medium, and the shake-flask fermentation was carried out by TB medium. The fermentation medium used in the 3-L fermenter contained $\left(\mathrm{g} \mathrm{L}^{-1}\right) 15.0$ industrial peptone, 15.0 corn syrup, $1.0\left(\mathrm{NH}_{4}\right)_{2}$-H-citrate, $2.0 \mathrm{Na}_{2} \mathrm{SO}_{3}, 2.68\left(\mathrm{NH}_{4}\right)_{2} \mathrm{SO}_{4}$, and $19.2 \mathrm{~K}_{2} \mathrm{HPO}_{4}$, along with $3.0 \mathrm{~mL} \mathrm{~L}^{-1}$ trace element solution [19]. The feeding medium contained $\left(\mathrm{g} \mathrm{L}^{-1}\right) 200.0$ industrial yeast powder and 300.0 glucose, along with $20.0 \mathrm{~mL} \mathrm{~L}^{-1}$ trace element solution.

\section{Plasmids construction and transformation}

All plasmids and primers used in this study are listed in Table 2 and Additional file 1: Table S1, respectively. The $\alpha$-amylase gene amyS was amplified from pET-20b-amy [4] using primers $\mathrm{pBE} 1$ and $\mathrm{pBE} 2$ and then cloned into the vector pBE-S DNA using restriction enzymes $S a c$ I and HindIII, creating the plasmid pBE-SP $\mathrm{aprE}^{-a m y S}$. The pBE-amys fragment (backbone of $\mathrm{pBE}^{-\mathrm{SP}_{\text {mix }}-a m y S \text { ) }}$ was obtained from $\mathrm{pBE}-\mathrm{SP}_{\mathrm{aprE}}-a m y S$ using primers $\mathrm{pBE} 3$ and $\mathrm{pBE} 4$. The isolated $\mathrm{pBE}-a m y S$ fragment was linked with 173 different $B$. subtilis-derived secretory signal peptides (purchase from Takara) using Takara's In-Fusion HD Cloning kit. The pHYQ fragment was amplified from plasmid pHYCGTd4 [19] using primers pHY1 and pHY2. The $\alpha$-amylase gene amyS was amplified from pET-20b-amy using primers $\mathrm{pHY} 3$ and $\mathrm{pHY} 4$ and then joined with the pHYQ fragment using Takara's In-Fusion HD Cloning kit to create pHYQamyS. The pHY fragment was amplified from plasmid pHYQamyS using primers pHY5 and pHY6. The $\mathrm{SP}_{\mathrm{RpmG}^{-}}$amyS, $\mathrm{SP}_{\mathrm{ApsB}}-a m y S$, and $\mathrm{SP}_{\mathrm{YojL}}$-amyS fragments were amplified from plasmids $\mathrm{pBE}-\mathrm{SP}_{\mathrm{RpmG}^{-}}-a m y S, \mathrm{pBE}-\mathrm{SP}_{\mathrm{ApsB}}-a m y S$ and $\mathrm{pBE}-\mathrm{SP}_{\mathrm{Yoi}}-a m y S$, respectively, using forward primers $\mathrm{pHY7}, \mathrm{pHY} 8$ and $\mathrm{pHY}$, respectively, and reverse primer pHY10. These fragments were joined with the pHY fragment using Takara's In-Fusion HD Cloning kits to create pHYRamyS, pHYAamyS, and pHYYamyS, respectively. The pHYQamyS and pHYYamyS fragments (backbones of pHYQamySP and pHYYamySP, respectively) were amplified from plasmids $\mathrm{pHYQ}$ amyS and pHYYamyS, respectively, using primers $\mathrm{pHY} 11$ and pHY12. The $\mathrm{P}_{\text {apr }}$-prs $A$ fragment was amplified from plasmid pHYPULd4P using primers pHY13 and pHY14 and then joined with the pHYQamyS and pHYYamyS fragments using Takara's In-Fusion HD Cloning kit to create pHYQamySP and pHYYamySP, respectively. Using the method of Anagnostopoulos and Spizizen [20], these

Table 1 Strains used in this study

\begin{tabular}{|c|c|c|}
\hline Strains & Properties & Reference \\
\hline \multicolumn{3}{|l|}{ Strains } \\
\hline E. coli JM109 & $\begin{array}{l}\text { endA1, recA1, thi, gyrA96, supE44, hsdR17 } \triangle \text { (lac-proAB)/F' [traD36, lacla', lacZ } \triangle \mathrm{M} 15 \text {, } \\
\left.\text { proAB } B^{+}\right]\end{array}$ & Takara \\
\hline E. coli BL21 & $\mathrm{F}^{-}$, ompT, hsd SB (rB- mB $\left.B^{-}\right)$, gal, dcm & Takara \\
\hline B. subtilis RIK1285 & Marburg 168 derivative: $\operatorname{trp} C 2$, lys 1, aprE $\triangle 3, n p r R 2, n p r E 18$ & Takara \\
\hline B. subtilis RIK1285AS & B. subtilis RIK1285 containing plasmid pBE-SP ${ }_{\text {AprE-amyS }}$ & This study \\
\hline B. subtilis WS11 & WS4 derivative, $\triangle w p r A, \Delta n p r B, \Delta v p r, \Delta e p r, \Delta b p r, \Delta m p r, \Delta a p r E$ & {$[23]$} \\
\hline B. subtilis WHS11 & WS11 derivative, $\triangle h r c A$ & Our laboratory \\
\hline WS11QS & B. subtilis WS11 containing plasmid pHYQamyS & This study \\
\hline WS11QSP & B. subtilis WS11 containing plasmid pHYQamySP & This study \\
\hline WS11RS & B. subtilis WS11 containing plasmid pHYRamyS & This study \\
\hline WS11AS & B. subtilis WS11 containing plasmid pHYAamyS & This study \\
\hline WS11YS & B. subtilis WS11 containing plasmid pHYYamyS & This study \\
\hline WS11YSP & B. subtilis WS11 containing plasmid pHYYamySP & This study \\
\hline WHS11YS & B. subtilis WHS11 containing plasmid pHYYamyS & This study \\
\hline WHS11YSA & B. subtilis WHS11 containing plasmid pHYYamySA & This study \\
\hline
\end{tabular}


Table 2 Plasmids used in this study

\begin{tabular}{|c|c|c|}
\hline Plasmids & Properties & References \\
\hline pBE-S DNA & $\operatorname{Amp}^{r}$ (E. coli), Kan' (B. subtilis), $\mathrm{P}_{\text {apre, }} \mathrm{SP}_{\text {aprE }}$ & Takara \\
\hline $\mathrm{pBE}-\mathrm{SP}_{\mathrm{mix}}$-amyS & $\operatorname{Amp}^{r}$ (E. coli), $\operatorname{Kan}^{r}$ (B. subtilis), $\mathrm{P}_{\text {aprE' }} \mathrm{SP}_{\text {mix }}$ a-amylase gene amyS & This study \\
\hline pBE-SP ${ }_{\text {AprE }}$-amyS & $\operatorname{Amp}^{r}$ (E. coli), Kan' (B. subtilis), $\mathrm{P}_{\mathrm{aprE},} \mathrm{SP}_{\mathrm{aprE}}$ a-amylase gene amyS & This study \\
\hline pBE-SP $\mathrm{RpmG}_{-}$-amyS, & $\operatorname{Amp}^{r}$ (E. coli), Kan' (B. subtilis), $P_{\text {apre, }}$ SP $P_{\text {RpmG }}$, a-amylase gene amyS & This study \\
\hline $\mathrm{pBE}-\mathrm{SP}_{\mathrm{ApsB}}-\mathrm{amyS}$ & $\mathrm{Amp}^{r}$ (E. coli), Kan' (B. subtilis), $\mathrm{P}_{\mathrm{aprE},} \mathrm{SP}_{\mathrm{ApsB}}$, a-amylase gene amyS & This study \\
\hline pBE-SP YojL-amyS & $\mathrm{Amp}^{r}$ (E. coli), Kan ${ }^{r}$ (B. subtilis), $\mathrm{P}_{\text {aprE, }} \mathrm{SP}_{\text {YojL' }}$ a-amylase gene amyS & This study \\
\hline pET-20b-amy & $\operatorname{Amp}^{r}($ E. coli), a-amylase gene & {$[4]$} \\
\hline pET24a-amyS' & $\operatorname{Kan}^{r}$ (E. coli), random mutant of a-amylase gene & This study \\
\hline pET24a-amySA & $\operatorname{Kan}^{r}$ (E. coli), a-amylase gene mutant amyS(K82E/S405R) & This study \\
\hline pHYCGTd4 & Amp $^{r}$ (E. coli), Tet ${ }^{r}$ (E. coli and B. subtilis), dual promoter $P_{\text {Hpall }}-P_{\text {amyQ }}$, SP AmyQ', $\beta$-CGTase gene & {$[19]$} \\
\hline pHYQamyS & pHYCGTd4 derivative, SP AmyQ', $_{\text {a-amylase gene amyS }}$ & This study \\
\hline pHYRamyS & pHYCGTd4 derivative, $\mathrm{SP}_{\text {RpmG }}$ a-amylase gene amyS & This study \\
\hline pHYAamyS & pHYCGTd4 derivative, $\mathrm{SP}_{\mathrm{ApsB}}$, $\mathrm{a}$-amylase gene amyS & This study \\
\hline pHYYamyS & pHYCGTd4 derivative, SP YojL, a-amylase gene amyS & This study \\
\hline pHYPULd4P & $\begin{array}{l}\text { Amp }^{r} \text { (E. coli), Tet }{ }^{r} \text { (E. coli and B. subtilis), dual promoter } P_{\text {Hpall }}-P_{\text {amyQ }}, P_{\text {apr }}, \beta-C G T a s e ~ g e n e, \\
\text { PrsA gene prsA }\end{array}$ & Our laboratory \\
\hline pHYQamySP & PHYQamyS derivative, PrsA gene prsA & This study \\
\hline pHYYamySP & PHYYamyS derivative, PrsA gene prsA & This study \\
\hline pHYYamySA & PHYYamyS derivative, a-amylase gene amySA & This study \\
\hline
\end{tabular}

protein expression vectors were transformed into $B$. subtilis. A library of mutant $\alpha$-amylase genes $\left(a m y S^{\prime}\right)$ was amplified from pET-20b-amy with primers pF1 and pR1 using error-prone PCR [21] and then cloned into the vector pET24a $(+)$ using restriction enzymes NcoI and HindIII, creating pET24a-amyS'. The carrier pET24a(+) had been modified in our laboratory with a pelB signal peptide. The recombinant vector pHYYamySA was obtained by replacing amyS in the recombinant vector pHYYamyS with the mutant K82E/S405R (amySA).

\section{Cultivation conditions \\ 96-well plate cultivation}

Seed solutions were prepared by adding single colonies to the wells of 96-well plates containing $600 \mu \mathrm{L}$ of $\mathrm{LB}$ medium supplemented with $30 \mathrm{mg} \mathrm{L}^{-1}$ kanamycin; the inoculated plates were cultured at $37{ }^{\circ} \mathrm{C}$ and $900 \mathrm{rpm}$ for $8 \mathrm{~h}$. Aliquots of these seed cultures $(50 \mu \mathrm{L})$ were then transferred to a new 96-well plate containing $600 \mu \mathrm{L} \mathrm{TB}$ medium supplemented with $30 \mathrm{mg} \mathrm{L}^{-1}$ kanamycin. These plates were incubated at $37^{\circ} \mathrm{C}$ and $900 \mathrm{rpm}$ for $2 \mathrm{~h}$, then at $33^{\circ} \mathrm{C}$ and $900 \mathrm{rpm}$ for $48 \mathrm{~h}$.

\section{Shake flask cultivation}

Seed cultures were started by inoculating $10 \mathrm{~mL}$ of $\mathrm{LB}$ medium supplemented with $30 \mathrm{mg} \mathrm{L}^{-1}$ of the appropriate antibiotic in a $50 \mathrm{~mL}$ shake flask with a $20 \mu \mathrm{L}$ sample of frozen glycerol stock (stored at $-80{ }^{\circ} \mathrm{C}$ ). These cultures were incubated at $37^{\circ} \mathrm{C}$ and $200 \mathrm{rpm}$ for $8 \mathrm{~h}$. Aliquots of the seed culture $(5 \%[\mathrm{v} / \mathrm{v}])$ were then transferred to a $250 \mathrm{~mL}$ shake flask containing $50 \mathrm{~mL}$ TB medium supplemented with $30 \mathrm{mg} \mathrm{L}^{-1}$ of the appropriate antibiotic. These cultures were incubated at $37^{\circ} \mathrm{C}$ and $200 \mathrm{rpm}$ for $2 \mathrm{~h}$, and then at $33{ }^{\circ} \mathrm{C}$ and $200 \mathrm{rpm}$ for $48 \mathrm{~h}$. The culture supernatant, which was used as the crude enzyme solution, was obtained by centrifugation at $12,000 \mathrm{~g}$ for $15 \mathrm{~min}$ at $4{ }^{\circ} \mathrm{C}$.

\section{3-L Bioreactor cultivation}

Seed cultures was started by inoculating $50 \mathrm{~mL}$ of $\mathrm{LB}$ medium in a $250 \mathrm{~mL}$ shake flask with a $100 \mu \mathrm{L}$ sample of frozen glycerol stock (stored at $-80{ }^{\circ} \mathrm{C}$ ). The resulting cultures were incubated at $37{ }^{\circ} \mathrm{C}$ and $200 \mathrm{rpm}$ for $10 \mathrm{~h}$. In a 3-L fermenter (Labfors, Infors-HT Co., Ltd), the fermentation medium was inoculated with seed cultures in a ratio of $10 \%(\mathrm{v} / \mathrm{v})$, and $20 \mathrm{mg} \mathrm{L}^{-1}$ tetracycline was added to the fermentation medium every $24 \mathrm{~h}$. After inoculation, the fermentation was carried out at $37^{\circ} \mathrm{C}$, the $\mathrm{pH}$ was maintained at $7.0 \mathrm{using} 20 \%(\mathrm{v} / \mathrm{v}) \mathrm{H}_{3} \mathrm{PO}_{4}$ and $\mathrm{NH}_{4} \mathrm{OH}$, and the dissolved oxygen (DO) was maintained at approximately $30 \%$ by cascading the agitation speed (200 to $800 \mathrm{rpm}$ ) and injecting air mixed with pure oxygen. After approximately $8 \mathrm{~h}$ of culture, the DO suddenly increased and the agitation speed suddenly dropped, indicating that the initial glucose was completely consumed. At this point, fed-batch cultivation was initiated. The concentration of glucose in the medium was measured by SBA-40C biosensor (Biology Institute of 
Shandong Academy of Sciences, Jinan, China) and was maintained below $0.5 \mathrm{~g} \mathrm{~L}^{-1}$ by adjusting the feeding rate. At defined time intervals, the medium was sampled. The culture supernatant, which was used as the crude enzyme solution, was obtained by centrifugation at $12,000 \mathrm{~g}$ for $15 \min$ at $4{ }^{\circ} \mathrm{C}$.

\section{Determination of bacterial biomass}

To determine the dry cell weight (DCW), a $10 \mathrm{~mL}$ sample of the culture solution was centrifuged at $12,000 \mathrm{~g}$ and $4{ }^{\circ} \mathrm{C}$ for $15 \mathrm{~min}$. After removing the supernatant, the cell pellet was washed by resuspending it in $0.9 \%(\mathrm{w} / \mathrm{v}) \mathrm{NaCl}$ solution and centrifuging at $12,000 \mathrm{~g}, 4{ }^{\circ} \mathrm{C}$ for $15 \mathrm{~min}$. After repeating the wash with $0.9 \%(\mathrm{w} / \mathrm{v}) \mathrm{NaCl}$ solution, the supernatant was removed and the cell pellet was dried $105^{\circ} \mathrm{C}$ to constant weight.

\section{Construction of signal peptides library and a-amylase mutants library}

Takara's B. subtilis "Secretory Protein Expression System" and 173 B. subtilis signal peptides were used to identify the optimal signal peptide for $\alpha$-amylase. B. subtilis RIK1285 was transformed with recombinant vector pBE-SP $\mathrm{apre}^{-}$-amyS to construct the control strain B. subtilis RIK1285AS. The signal peptide screening library was constructed by replacing signal peptide $\mathrm{SP}_{\mathrm{aprE}}$ in the recombinant vector $\mathrm{pBE}-\mathrm{SP}_{\mathrm{aprE}}-$ amyS with 173 different $B$. subtilis-derived secretory signal peptides, and then using this library of vectors to transform $B$. subtilis RIK1285. A library of strains expressing random $\alpha$-amylase mutants was constructed by transforming $E$. coli BL21 with the vector pET24a-amyS .

\section{Enzyme activity assays and purification of a-amylase}

Qualitative screening of the library of random $\alpha$-amylase mutants was performed by cultivating individual colonies in 96-well plates and then using the culture supernatants to inoculate $1 \%$ agar plates containing $2 \%$ soluble starch. Assay plates were incubated at $60{ }^{\circ} \mathrm{C}$ for $90 \mathrm{~min}$, and then the $\alpha$-amylase activity was evaluated by measuring the diameters of the clearance zones after staining with iodine. First, a clear circle larger than that produced by the control strain was selected by visual observation; then, the diameters of the two were measured with a ruler, and the ratio of the diameter of the selected clear circle to the diameter of the control clear circle was calculated. When the ratio was greater than 1.5, the larger the value, the higher the fermentation supernatant amylase activity of the strain corresponding to the clear circle. When qualitatively measuring amylase activity, each sample was tested three times, and the data were analysed according to the methods in "Statistical analysis" section of "Materials and methods". A quantitative $\alpha$-amylase activity assay was performed by measuring the amount of reducing sugar released from soluble starch. The amount of reducing sugar was determined using the 3,5-dinitrosalicylic acid (DNS) method [22]. Briefly, a $2.0 \mathrm{~mL}$ assay mixture containing $0.1 \mathrm{~mL}$ of crude enzyme extract and $1.0 \mathrm{~mL} 1 \%$ soluble starch in $20 \mathrm{mM}$ sodium phosphate buffer $(0.9 \mathrm{~mL}$ with $\mathrm{pH} 6.0)$ was incubated at $70{ }^{\circ} \mathrm{C}$ for $5 \mathrm{~min}$, at which point $3 \mathrm{~mL}$ of DNS solution was added to terminate the reaction. This reaction mixture was boiled for $7 \mathrm{~min}$; then, $10 \mathrm{~mL}$ of deionized water was added, and the absorbance of the mixture at $540 \mathrm{~nm}$ was measured. One unit of $\alpha$-amylase activity was defined as the amount of enzyme that released $1 \mu \mathrm{mol}$ of reducing sugar per min from soluble starch under the assay conditions described above. Purification of the wild-type (AmyS) and mutant (AmySA) enzymes was performed according to the method described by Li et al. [4]. The optimal temperatures of AmyS and AmySA were determined by assaying protein samples at $60-90{ }^{\circ} \mathrm{C}$ in $20 \mathrm{mM}$ phosphate buffer ( $\mathrm{pH}$ 6.0). The optimal $\mathrm{pH}$ of AmyS and AmySA were determined by measuring the enzyme activity at $70{ }^{\circ} \mathrm{C}$ in $20 \mathrm{mM}$ citrate buffers ( $\left.\mathrm{pH} 4.5-6.0\right)$ and $20 \mathrm{mM}$ phosphate buffers (pH 5.5-7.5), respectively. The enzyme activities at different temperatures and $\mathrm{pH}$ values were expressed as a percentage of the highest activity.

The temperature stability of AmyS and AmySA were determined at $90^{\circ} \mathrm{C}$ in $20 \mathrm{mM}$ phosphate buffer, $\mathrm{pH}$ 6.0, containing $1 \mathrm{mM} \mathrm{Ca}^{2+}$. Timed aliquots were removed from incubations; after centrifugation of sample at $12,000 \mathrm{~g}$ and $4{ }^{\circ} \mathrm{C}$ for $15 \mathrm{~min}$, the $\alpha$-amylase enzyme activity present in the supernatant was measured. The sample enzyme activity values of other sampled times were expressed as a percentage of the $0 \mathrm{~h}$ sample activity.

\section{SDS-PAGE gel electrophoresis}

The crude enzyme solution containing the target protein was mixed with $5 \times$ protein loading buffer, boiled in boiling water for $10 \mathrm{~min}$, and then analysed using sodium dodecyl sulfate-polyacrylamide gel electrophoresis (SDSPAGE) with a $10 \%$ separation gel. Prior to cell disruption, the cell paste was diluted to a density $\left(\mathrm{OD}_{600}\right)$ of 5 and treated with lysozyme for $30 \mathrm{~min}$. The cells were disrupted with an Ultrasonic Homogenizer (Ningbo Xinzhi Biotechnology Co., Ltd. Ningbo, China) for $10 \mathrm{~min}$ at $20 \%$ power using the cycle: work $2 \mathrm{~s}$, stop $3 \mathrm{~s}$. After centrifugation at $12,000 \mathrm{~g}$ for $15 \mathrm{~min}$ at $4{ }^{\circ} \mathrm{C}$, the supernatant was thoroughly separated from the pellet fragments. A $20 \mu \mathrm{L}$ sample of the supernatant and $5 \mu \mathrm{L}$ of $5 \times$ protein loading buffer were boiled for $10 \mathrm{~min}$; then, an $8 \mu \mathrm{L}$ portion of this mixture was used for electrophoresis as the cell disruption supernatant. A $20 \mu \mathrm{L}$ aliquot of $5 \times$ protein loading buffer was added to the bacterial debris, and the resulting mixture was boiled for $10 \mathrm{~min}$. 
After centrifugation at $12,000 g$ for $3 \mathrm{~min}$ at $4{ }^{\circ} \mathrm{C}$, a $3 \mu \mathrm{L}$ portion was used for electrophoresis as the cell disruption precipitate. Coomassie Brilliant Blue R-250 was used to stain protein bands.

\section{Statistical analysis}

All experiments were conducted three times, and the data are presented as the averages \pm standard deviation. Statistical analyses were conducted using a t test, and the variance at $\mathrm{P}<0.05$ was considered statistically significant.

\section{Results and discussion}

Heterologous expression of B. stearothermophilus a-amylase in $B$. subtilis WS11

To produce $B$. stearothermophilus $\alpha$-amylase (AmyS) in $B$. subtilis, the expression strain WS11QS was constructed by transforming $B$. subtilis WS11 with the recombinant vector pHYQamyS, which contained the $\alpha$-amylase gene amyS. WS11QS was cultured in a $250 \mathrm{~mL}$ triangular shake flask containing $50 \mathrm{~mL}$ of $\mathrm{TB}$ medium for $2 \mathrm{~h}$ at $37^{\circ} \mathrm{C}$, and then shifted to $33^{\circ} \mathrm{C}$ for $48 \mathrm{~h}$ to produce $\alpha$-amylase. The $\alpha$-amylase activity present in the culture supernatant was $210.4 \mathrm{U} \mathrm{mL}^{-1}$. To investigate the distribution of AmyS within WS11QS, cultured cells were treated with lysozyme for $30 \mathrm{~min}$, and then disrupted using a sonicator. SDS-PAGE analysis showed that the culture supernatant, the disruption supernatant, and the disruption precipitate obtained from WS11QS had no obvious bands near $55 \mathrm{kDa}$, which corresponds to the molecular weight of the $\alpha$-amylase protein (Fig. 1). This indicates that the expression level of $\alpha$-amylase in the recombinant WS11QS was very low.

\section{Isolation and identification of optimal signal peptides for a-amylase}

To determine which $B$. subtilis signal peptide would be the best to use with AmyS, N-terminal fusions of AmyS with 173 different $B$. subtilis signal peptides were produced using a commercial screening kit. Individual strains were cultured in 96-well plates, and the activity of AmyS present in the culture supernatants were evaluated by comparing the diameters of the clear circles formed by the culture supernatants on soluble starch plates. After screening 1200 strains, the three strains with the largest transparent circle diameters were selected and fermented in a triangular shake flask to verify their ability to produce $\alpha$-amylase (Fig. 2a). After $48 \mathrm{~h}$ of shake-flask culture, the $\alpha$-amylase activities of strains $a, b, c$ and control strain $d$ were $212.4,329.9,246.1$, and $63.9 \mathrm{U} \mathrm{mL}^{-1}$, respectively (Fig. 2b). The signal peptides present in strains a-c, identified by sequencing of the expression plasmids, were $\mathrm{SP}_{\text {YojL }}, \mathrm{SP}_{\mathrm{RpmG}}$, and $\mathrm{SP}_{\mathrm{AspB}}$, respectively (Table 3 ).

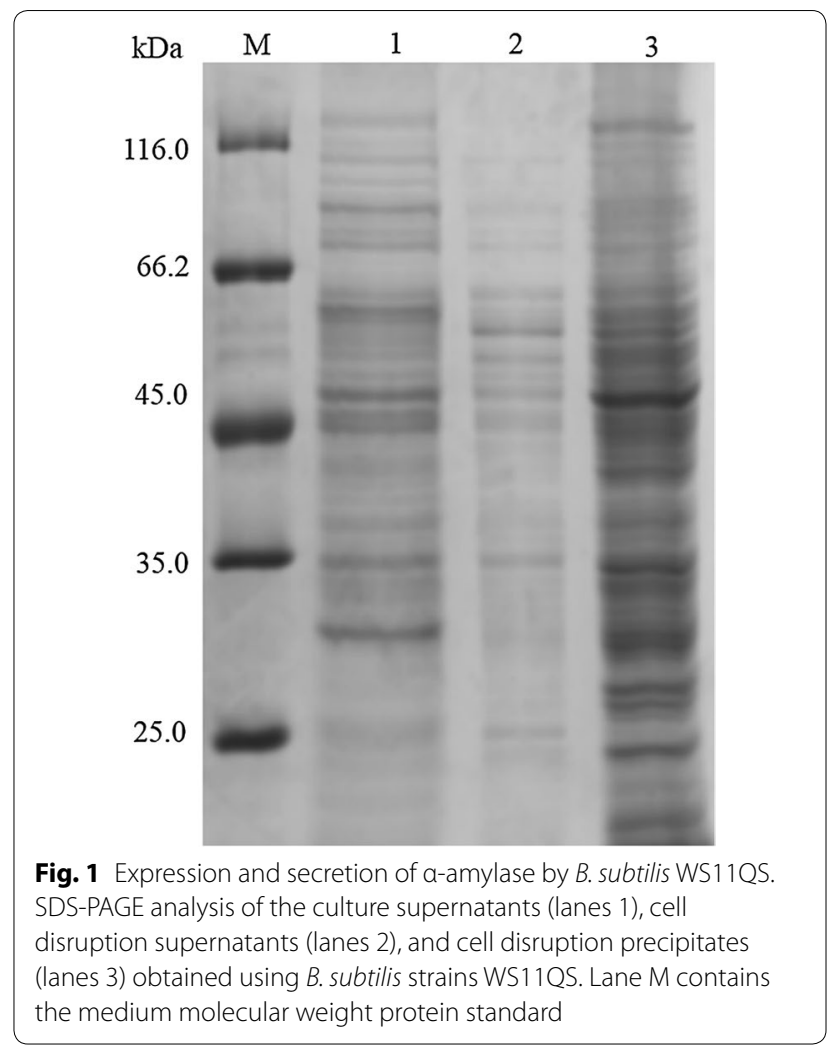

To further characterize the levels of AmyS produced using each of these signal peptides, we introduced them into an expression system previously constructed in our laboratory [23]. This system uses the expression plasmid pHYCGTd4, which contains the dual promoters $P_{\text {HpaII }}$ and $\mathrm{P}_{\mathrm{AmyQ}}$, and the expression strain B. subtilis WS11, which has had the genes encoding eight proteases (wprA, $n p r B, v p r$, epr, bpr, aprE, nprE and mpr) deleted from its genome to minimize the degradation of exogenous recombinant proteins. The results of this effort, recombinant strain WS11RS, WS11AS, and WS11YS, express AmyS fused to the signal peptides $\mathrm{SP}_{\mathrm{RpmG}}, \mathrm{SP}_{\mathrm{AspB}}$ and $\mathrm{SP}_{\text {YojL }}$, respectively, was constructed. After $48 \mathrm{~h}$ of cultivation in a triangular shake flask, the $\alpha$-amylase activities of the extracellular supernatants of WS11RS, WS11AS, and WS11YS were $334.3,315.1$, and $732.0 \mathrm{U} \mathrm{mL}^{-1}$, respectively (Fig. 3a). In contrast to the results obtained with WS11QS (Fig. 1), SDS-PAGE analysis of the cell disruption precipitates of the WS11RS, WS11AS, and WS11YS showed obvious inclusion bodies (Fig. 3b). Because the culture supernatant of the recombinant strain WS11YS had by far the highest enzyme activity, this was the only strain studied in subsequent experiments.

To determine the location of the inclusion bodies formed in WS11YS, their N-terminal amino acid sequence was determined. The amino acid sequence 

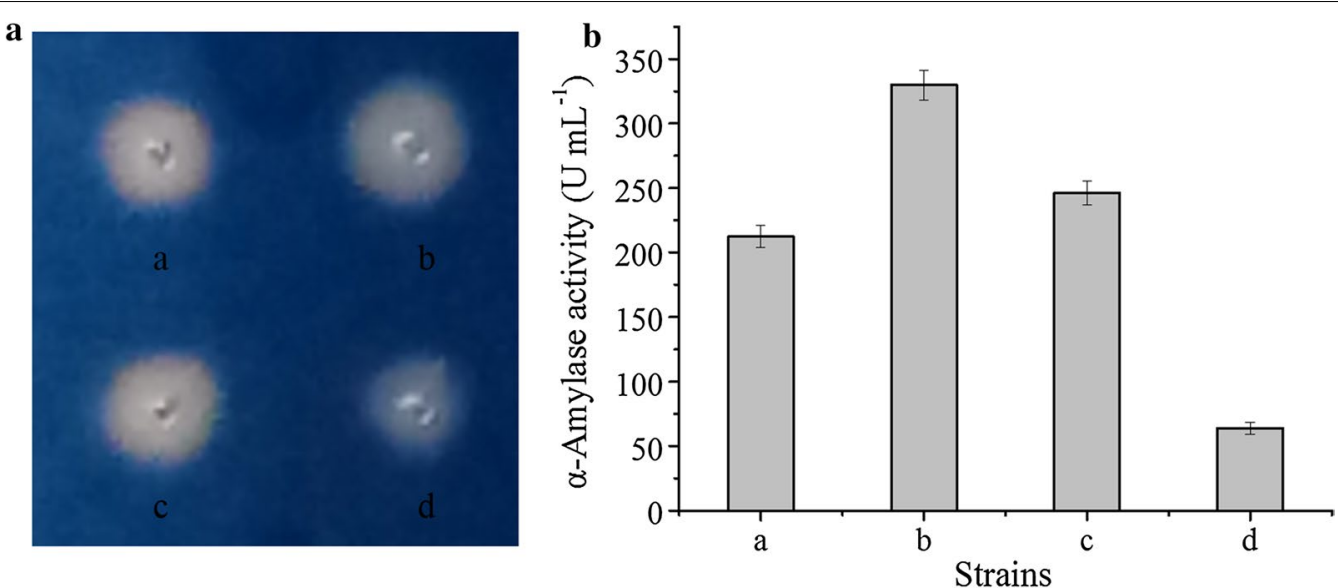

Fig. 2 Screening of a-amylases containing different signal peptides. a Transparent circles formed on a soluble starch plate by B. subtilis RIK1285 strains containing a-amylase variants with different signal peptides. b Alpha-amylase activities of the extracellular supernatants obtained using $B$. subtilis RIK1285 strains cultured in a triangular shake flask. Strains a, b, and c represent three B. subtilis RIK1285 variants that produce a-amylase with different signal peptides; $d$ is a control strain. Error bars indicate the standard deviation from the mean of the three experimental data replicates

Table 3 Characteristics of selected signal peptides

\begin{tabular}{llll}
\hline Signal peptides & Protein sequence & Type & SPase \\
\hline $\mathrm{SP}_{\text {RpmG }}$ & MRKKITLACKTCGNRNYTTMKSSASA & Sec & SPase I \\
$\mathrm{SP}_{\text {AspB }}$ & MKLAKRVSALTPSTTLAITAKA & Sec & SPase I \\
$\mathrm{SP}_{\text {YojL }}$ & MKKKIVAGLAVSAVVGSSMAAAPAEA & Sec & SPase I \\
\hline
\end{tabular}

obtained, Met-Lys-Lys-Lys-Ile (Additional file 1: Figure S1), was consistent with the first five amino acids of the signal peptide $\mathrm{SP}_{\mathrm{YojL}}$ (Table 3). This indicates that the inclusion bodies are formed within the cell by aggregation of the $\alpha$-amylase protein precursor.
The efficiency of protein precursor transmembrane transport is related to the amino acid sequences of the signal peptide and the mature protein, as well as their interaction with related intracellular elements [24-27]. Despite substantial effort, the specific relationship between signal peptide and target protein remains poorly understood [28]. For a specific protein, a signal peptide with higher hydrophobicity [29], stronger $\alpha$-helix preference of the amino acid at the end of the $\mathrm{H}$ domain [15], and higher N-terminal amino acid charge, generally gives higher translocation efficiency. Because signal peptide $\mathrm{SP}_{\text {YojL }}$ displays poorer hydrophobicity, $\alpha$-helix preference of the amino acid at the end of the
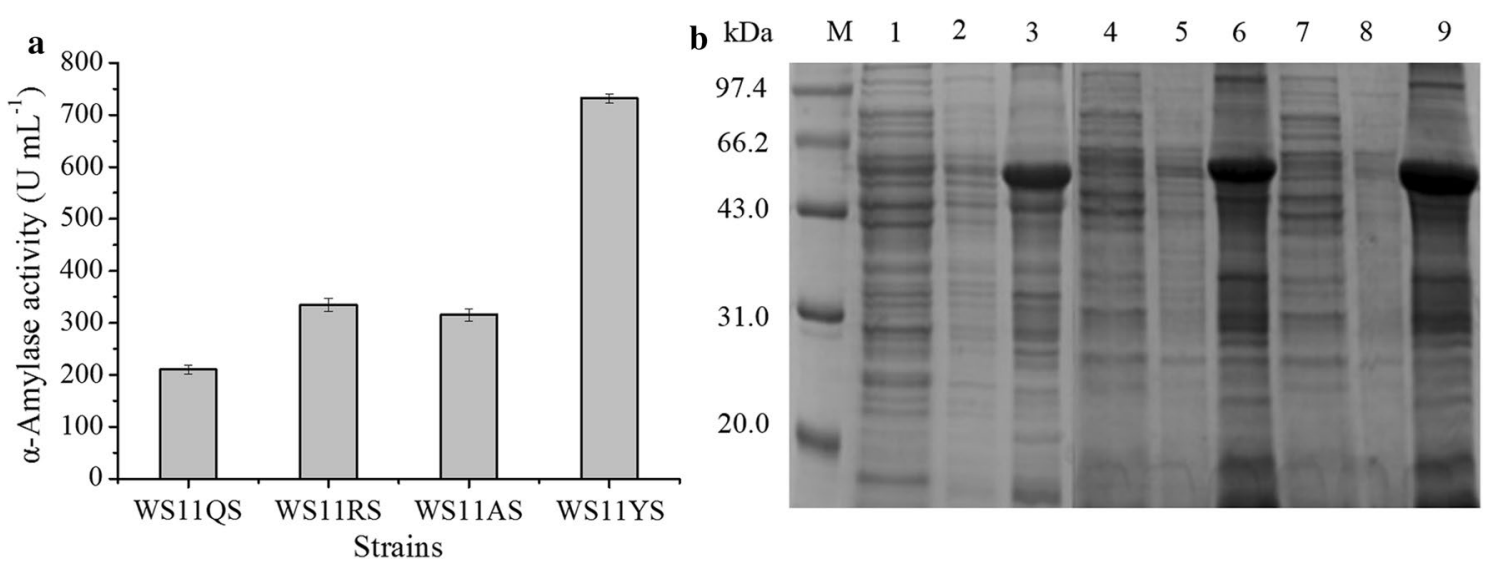

Fig. 3 Expression and secretion of a-amylase by B. subtilis WS11 variants. a Alpha-amylase activity in the shake-flask culture supernatants obtained using B. subtilis WS11 variants. b SDS-PAGE analysis of the culture supernatants (lanes 1, 4, and 7), cell disruption supernatants (lanes 2, 5, and 8), and cell disruption precipitates (lanes 3, 6, and 9) obtained using B. subtilis strains WS1 1RS, WS11AS, and WS11YS, respectively. Lane M contains the medium molecular weight protein standard. Error bars indicate the standard deviation from the mean of the three experimental data replicates 
$\mathrm{H}$ domain, and positive charge of the $\mathrm{N}$-terminal amino acid than signal peptide $\mathrm{SP}_{\mathrm{AmyQ}^{\prime}}$ (Table 4), it is reasonable to predict that for the $\alpha$-amylase protein, $\mathrm{SP}_{\text {YoiL }}$ would provide lower transmembrane efficiency, which refers to the rate of amylase precursor transfer to the outer side of the plasma membrane through the plasma membrane channel under the guidance of a signal peptide, than signal peptide $\mathrm{SP}_{\mathrm{AmyQ}}$. Thus, the greater extracellular amylase activity caused by $\mathrm{SP}_{\mathrm{YojL}}$, compared with that obtained using $\mathrm{SP}_{\mathrm{Amy}^{\prime}}$, is likely associated with a decrease in the intracellular transmembrane transport rate of the corresponding amylase protein precursors.

Caspers et al. [30] reported a similar phenomenon. They performed saturation mutagenesis of the amino acids in positions $2-7$ of the signal peptide region of $B$. subtilis $\alpha$-amylase and used this sequence to direct the extracellular expression of cutinase from $F$. solani pisi in B. subtilis. They found that some of the signal peptide mutants increased the production of $F$. solani pisi cutinase in the growth medium. Pulse-chase experiments with the corresponding protein precursors revealed that some of the cutinase protein precursors containing these mutant signal peptides crossed the membrane at a lower rate.

Sarvas et al. [31] suggested that highly efficient targeting and translocation of protein precursors to the cell membrane transport system may overload PrsA, a molecular chaperone attached to the cytoplasmic membrane of B. subtilis [32]. Many studies have shown that PrsA promotes $\alpha$-amylase folding in B. subtilis, thereby increasing $\alpha$-amylase extracellular production levels [33]. Convinced that the number of PrsA molecules on the cell membrane should be sufficient [9], Yan and Wu [34] suggested that some of the PrsA molecules attached

\begin{tabular}{llll}
$\begin{array}{l}\text { Table } 4 \text { Characteristics } \\
\text { and } \mathbf{S P}_{\text {YojL }}\end{array}$ & signal peptides & $\mathbf{S P}_{\text {Amy }^{\prime}}$ \\
\hline Signal peptides & Hydrophobicity & $\begin{array}{l}\text { a-Spiral } \\
\text { preference }\end{array}$ & $\begin{array}{l}\mathbf{N} \\
\text { domain } \\
\text { charge }^{\mathbf{c}}\end{array}$ \\
\hline $\mathrm{SP}_{\text {AmyQ }^{\prime}}$ & 41.5 & 1.41 & 53.84 \\
$\mathrm{SP}_{\text {YojL }}$ & 33 & 0.34 & 34.96 \\
\hline
\end{tabular}

a Hydrophobicity: The value of the sum of the hydrophobicity of the $\mathrm{H}$ domain was calculated using the ProtScale tool (https://web.expasy.org/protscale/ pscale/Hphob.Doolittle.html) [42]. The higher the value, the stronger the hydrophobicity

${ }^{b}$ a-Spiral preference: The conformational preference of amino acids was determined using the tables in Proteins Structure and Function [43]. The higher the value, the stronger the preference of the a-spiral

${ }^{c} \mathrm{~N}$ domain charge: The sum of the charges on the $\mathrm{N}$-terminal amino acid of the signal peptide was calculated from the sum of the isoelectric points of the $\mathrm{N}$-terminal amino acids to the cell membrane are far from the Sec-dependent secretion system; otherwise, there would be no need to have so many PrsA molecules. In other words, we can speculate that the effective amount of PrsA attached to the cell membrane, the amount that interacts with the Sec-dependent secretion pathway, is insufficient. Therefore, when the intracellular protein precursor is secreted faster, the effective amount of PrsA is insufficient, causing the incorrectly folded protein to accumulate on the outer side of the cell plasma membrane. This accumulation causes the CrssRS reaction, which induces the production quality control proteases, HtrA and HtrB [35]. These proteases then degrade the $\alpha$-amylase secreted by the Sec-dependent secretion pathway. However, when the secretion of the intracellular protein precursor is slower, the effective amount of PrsA is relatively sufficient. Under these conditions, the decreased accumulation of incorrectly folded protein on the outer side of the plasma membrane weakens the CrssRS reaction and produces little or no HtrA and HtrB quality control proteases. As a result, degradation of the $\alpha$-amylase secreted by the Sec-dependent secretion pathway is decreased, increasing the extracellular $\alpha$-amylase activity. However, when intracellular protein precursor secretion is slower, a greater number of $\alpha$-amylase protein precursors fail to cross the plasma membrane, which leads to the formation of inclusion bodies that can be detected using SDSPAGE (Fig. 3b).

To test the above hypothesis, we constructed two recombinant $B$. subtilis strains that overexpress PrsA: WS11QSP, which expresses AmyS with the SP ${ }_{\text {AmyQ }}$ signal sequence, and WS11YSP, which expresses AmyS with the $\mathrm{SP}_{\text {YoiL }}$ signal sequence. After $48 \mathrm{~h}$ of fermentation in shake flasks, the $\alpha$-amylase activities of the culture supernatants of WS11QSP and WS11YSP were 598.8 and $712.1 \mathrm{U} \mathrm{mL}^{-1}$, respectively. Therefore, WS11QSP represents a 2.85 -fold improvement in extracellular $\alpha$-amylase activity over WS11QS (210.4 $\mathrm{U} \mathrm{mL}^{-1}$ ), while WS11YSP produced only $97 \%$ of the $\alpha$-amylase activity produced by WS11YS (732.0 $\left.\mathrm{U} \mathrm{mL}^{-1}\right)$. These data indicate a PrsA deficit in WS11QS that is absent in WS11YS, consistent with the suggestion that lowering the secretion rate prevents the overloading of PrsA.

\section{Reduce inclusion bodies by overexpressing intracellular molecular chaperones}

Most of the extracellularly secreted protein is properly folded within the cell so that it can be effectively transported across the cell membrane. Intracellular molecular chaperones play a major role in maintaining this conformational state [15]. GroEL-GroES and DnaKDnaJ-GrpE are among the most important chaperone complexes, and they generally exhibit different effects 
on increasing protein solubility [36]. We cannot, at present, confidently predict which molecular chaperone contributes to the successful secretion of a specific protein. Overexpression of a single molecular chaperone can sometimes cause a defect in cell septation and the formation of cell filaments, which are harmful to the bacteria [37], so it is usually necessary to overexpress both GroEL-GroES and DnaK-DnaJ-GrpE.

Mogk et al. [38] reported that these two operons are co-regulated by the repressor HrcA, while HrcA activity is regulated by GroE. Inactivation of the $h r c A$ gene enables overexpression of both series of intracellular chaperone proteins [39]. Because our laboratory previously constructed WHS11, a WS11 variant in which the $h r c A$ gene has been inactivated, this strain was transformed with the expression vector pHYYamyS. After shake-flask fermentation for $48 \mathrm{~h}$, the $\alpha$-amylase activity of the culture supernatant from WHS11YS was $1039.4 \mathrm{U} \mathrm{mL}^{-1}$, which was 1.42-fold greater than that of WS11YS (732.0 $\left.\mathrm{U} \mathrm{mL}^{-1}\right)$. As seen in Fig. 4, the inclusion body content of WHS11YS was significantly smaller than that of WS11YS, but there were still some inclusion bodies. Wu et al. [40] reported similar results when expressing an anti-digoxigenin single-chain antibody. In their study, inactivating the $h r c A$ gene resulted in the coordinated overproduction of GroEL-GroES and DnaK-DnaJGrpE, which improved secretion of the antibody, which easily formed inclusion bodies, by approximately $60 \%$.

\section{High-throughput screening of $a$-amylase mutants}

The heterologous expression level of a foreign protein is related to its primary sequence [41]. Error-prone PCR combined with high-throughput screening technology is an important means to create and screen libraries of enzyme mutants to identify variants with improved properties. In this study, we used error-prone PCR to construct a library of $\alpha$-amylase mutants through random mutation of the amyS sequence. These mutants were screened by determining the diameters of the clear circles formed on $2 \%$ soluble starch plates. Because these clear circles were formed via $\alpha$-amylase activity, the screening assay was able to rapidly identify mutants with enhanced $\alpha$-amylase activity.

For the sake of convenience, plasmid vector pET24a(+) and host E. coli BL21(DE3) were used to express the library of $\alpha$-amylase mutants. After screening 5000 strains, a single strain that formed the largest transparent circle on the starch plate was selected for verification via shake-flask culture. The protein produced by this strain, which was found to contain the double mutation K82E/ S405R (AmySA), had $\alpha$-amylase activity that was 2.1-fold greater than that of wild-type AmyS.

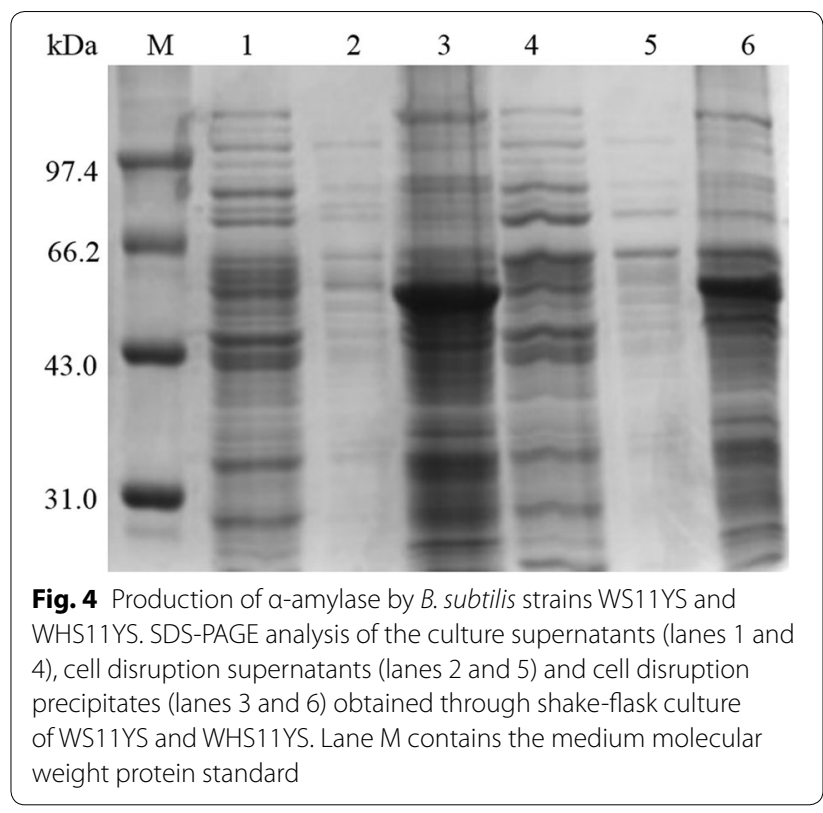

To compare the enzymatic properties of AmyS and its mutant AmySA, these proteins were produced in $E$. coli, purified, and then characterized. The specific activities of AmyS and AmySA were $28,260 \mathrm{U} \mathrm{mg}^{-1}$ and $29,070 \mathrm{U} \mathrm{mg}^{-1}$, respectively. As shown in Fig. 5a, AmySA has the same optimum temperature $\left(75^{\circ} \mathrm{C}\right)$ as AmyS. At temperatures $>75^{\circ} \mathrm{C}$, the rate of decline in enzyme activity of AmySA was slightly higher than that of AmyS, but the difference was barely noticeable. The enzyme activities of AmyS and AmySA at $90{ }^{\circ} \mathrm{C}$ were $41.6 \%$ and $38.7 \%$ of that at $75{ }^{\circ} \mathrm{C}$, respectively. As shown in Fig. 5b, AmyS and AmySA shared the same optimum $\mathrm{pH}(\mathrm{pH}$ 6.0), and at same $\mathrm{pH}$, their activities were greater in phosphate buffer than in citrate buffer. At $90{ }^{\circ} \mathrm{C}$ and $\mathrm{pH}$ 6.0, in the presence of $1 \mathrm{mM} \mathrm{Ca}^{2+}$, AmyS and AmySA showed similar thermal stability. After $3 \mathrm{~h}$, the enzyme activities of AmyS and AmySA remained $42.5 \%$ and $41.1 \%$, respectively, of their original activities at $70{ }^{\circ} \mathrm{C}$ (Fig. 5c).

To assess the extracellular production level of AmySA in B. subtilis, strain WHS11YSA was constructed. This strain, which is otherwise identical to the wild-type $\alpha$-amylase expression strain WHS11YS, was cultured in a triangular shake flask for $48 \mathrm{~h}$. The $\alpha$-amylase activity of the supernatant $\left(1496.8 \mathrm{U} \mathrm{mL}^{-1}\right)$ was 1.44-fold greater than that of WHS11YS $\left(1039.4 \mathrm{U} \mathrm{mL}^{-1}\right)$. It is interesting that the degree of increase obtained using $B$. subtilis as the expression host (1.44-fold improvement) was lower than that observed when using E. coli BL21 as the expression host (2.1-fold improvement). This may be due to differences in the physiological characteristics of the two host strains and differences in the expression vectors used in these hosts. 

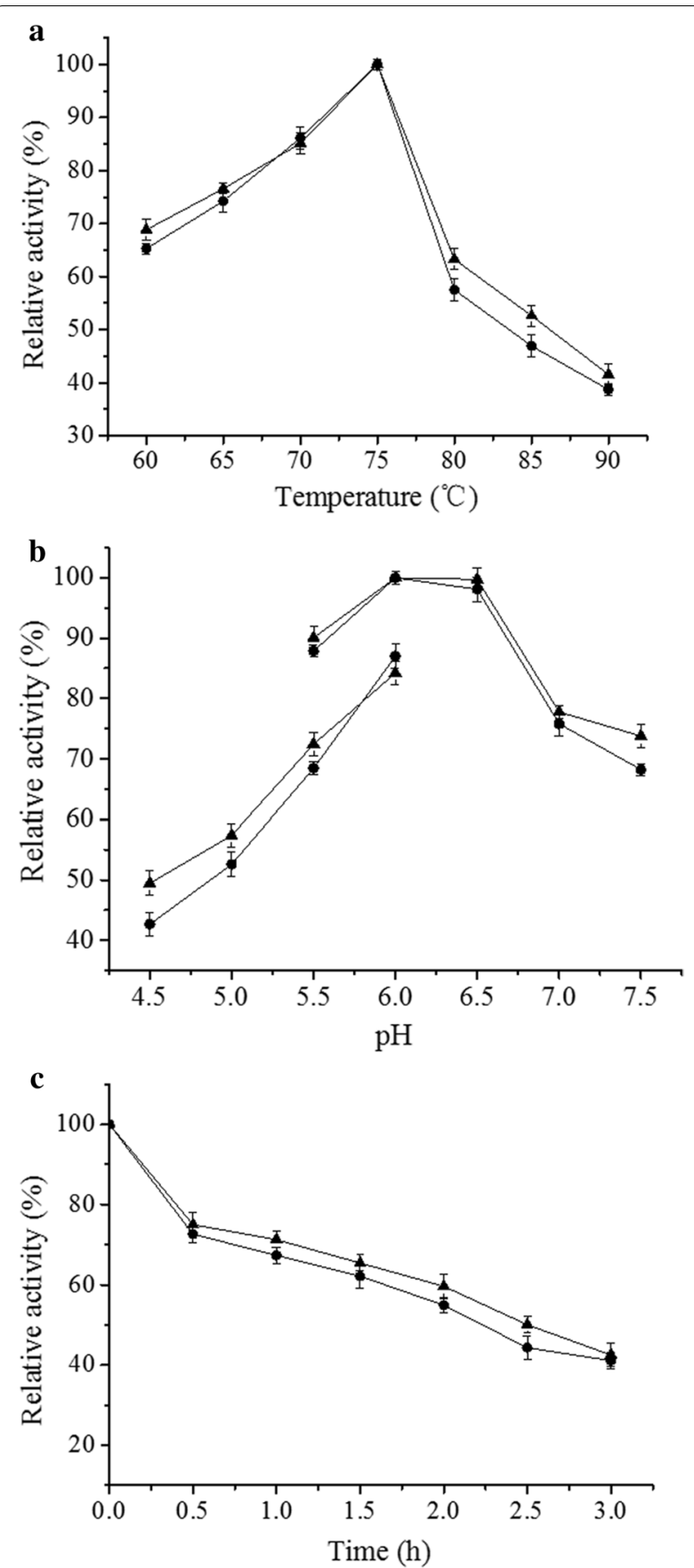

Fig. 5 Effect of temperature and pH on the a-amylase activities of AmyS and AmySA. a Effect of temperature. $\mathbf{b}$ Effect of $\mathrm{pH}$. $\mathbf{c}$ Thermal stability of AmyS and AmySA at $90^{\circ} \mathrm{C}, \mathrm{pH} 6.0$, and $1 \mathrm{mM} \mathrm{Ca}^{2+}$. Filled triangle, AmyS; filled circle, AmySA. Error bars indicate the standard deviation from the mean of the three experimental data replicates

\section{Scale-up of a-amylase production in a 3-L fermenter}

In the experiment described above, after $48 \mathrm{~h}$ of shake flask fermentation, the $\alpha$-amylase activities in the fermentation supernatants of WS11YS, WHS11YS, and
WHS11YSA were 3.5-, 4.9- and 7.1-fold greater than that of the original strain WS11QS, respectively. To verify whether all manipulations performed to increase activity of $\alpha$-amylase detected in culture supernatant during the shake flask fermentation were indeed significantly different from that observed for parental strain WS11QS, the strains WS11QS, WS11YS, WHS11YS, and WHS11YSA were subjected to 3-L fermenter fermentation verification (Fig. 6).

When the carbon source in the initial culture was consumed, a feed medium was added. During fermentation in the 3-L fermenter, the $\alpha$-amylase activities in the fermentation supernatants of strains WS11QS, WS11YS, WHS11YS and WHS11YSA reached peak levels at 86, 88, 88 and $92 \mathrm{~h}$, respectively, and the highest amylase enzyme activities were 4293.9, 6337.8, 7728.9 and $9201.1 \mathrm{U} \mathrm{mL}^{-1}$, respectively. These were 20.4-, 8.7-, 7.4- and 6.1-fold greater than the amylase activity in the fermentation supernatant at $48 \mathrm{~h}$ of the corresponding strain in shake flask fermentation, respectively. The reason that the highest amylase activity obtained by fermentation of different strains in 3-L fermenter had a different increase than the amylase activity obtained by shake flask fermentation supernatant may be because the fermentation medium used by all strains in the 3-L fermenter fermentation process is our optimal fermentation medium optimized for WS11QS, which may not be the optimum fermentation medium for other strains.

The highest amylase activity in the 3-L fermenter fermentation supernatant of the strain WHS11YSA was 2.1fold greater than that of the strain WS11QS. To compare this level with those previously reported, the $\alpha$-amylase activity of the supernatant obtained using WHS11YSA in the 3-L fermenter $\left(9021.1 \mathrm{U} \mathrm{mL}^{-1}\right)$ was 1.8 -fold greater than that obtained in a 7.5-L fermenter using B. subtilis 1A751pSP4 (5086 $\mathrm{U} \mathrm{mL}^{-1}$ ) [8], which is the highest heterologous extracellular production level that has been reported for $\alpha$-amylase from $B$. stearothermophilus in $B$. subtilis.

\section{Conclusions}

High-level expression of $B$. stearothermophilus $\alpha$-amylase in $B$. subtilis was achieved by screening optimal signal peptides, overexpressing chaperones, and performing random mutagenesis of the amylase gene. After $48 \mathrm{~h}$ of shake-flask culture, the $\alpha$-amylase activity of the supernatant of $B$. subtilis WHS11YSA (1496.8 $\mathrm{U} \mathrm{mL}^{-1}$ ) was 7.1 -fold greater than that of WS11QS (210.4 $\mathrm{U} \mathrm{mL}^{-1}$ ). After incubation for $92 \mathrm{~h}$ in a $3-\mathrm{L}$ fermenter, the $\alpha$-amylase activity that was obtained using WHS11YSA was $9201.1 \mathrm{U} \mathrm{mL}^{-1}$. This represents the highest amylase activity ever reported 

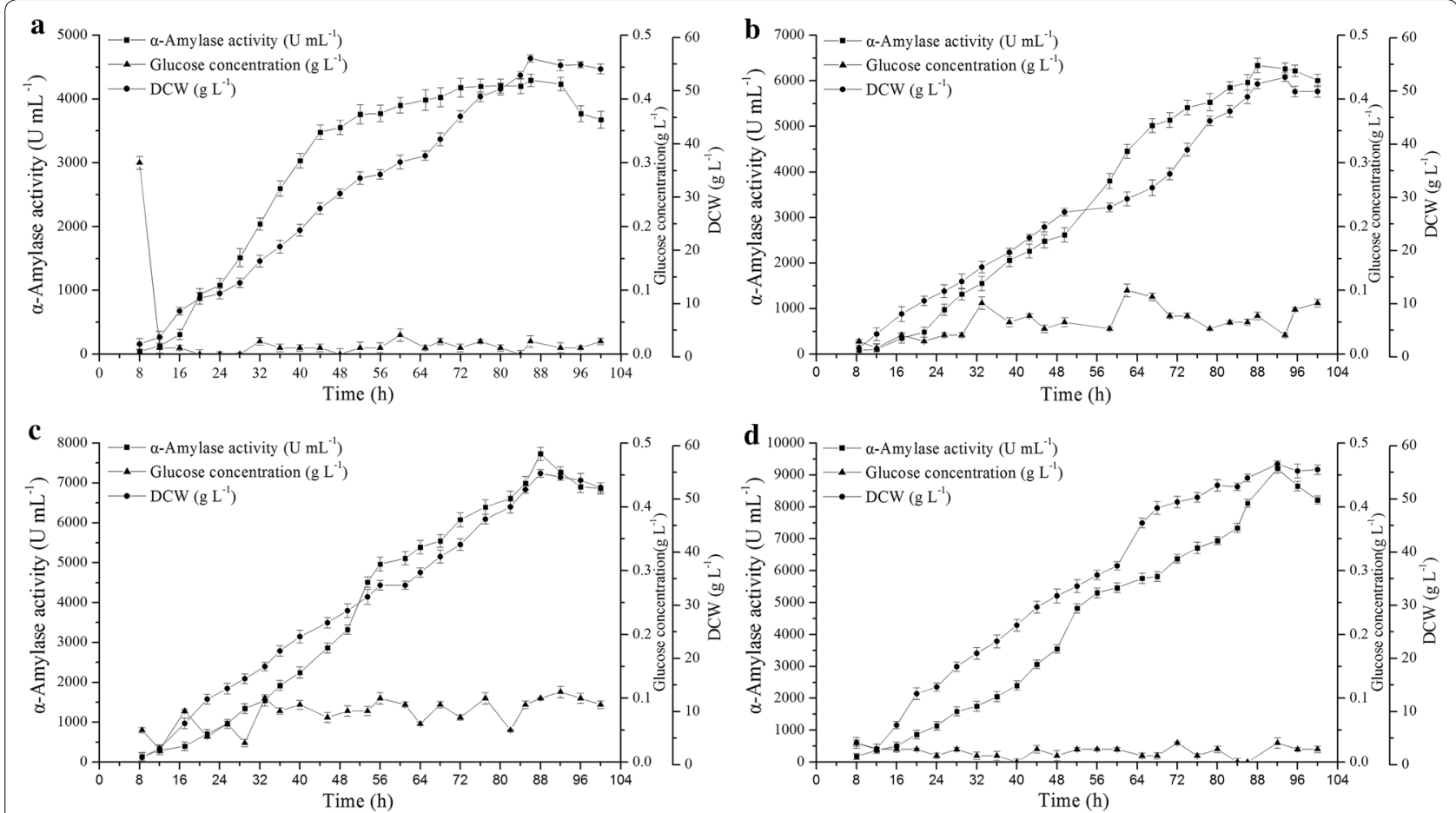

Fig. 6 Alpha-amylase production by various recombinant strains in a 3-L fermenter. a WS11QS, b WS11YS, c WHS11YS, dWHS11YSA. Error bars indicate the standard deviation from the mean of the three experimental data replicates

for $\alpha$-amylase from B. stearothermophilus in B. subtilis. This high-level expression lays a good foundation for enhanced industrial production of $\alpha$-amylase.

\section{Additional file}

Additional file 1: Figure S1. N-terminal amino acid sequence results of inclusion bodies. (A) Standard mixtures of 19 type PTH amino acids. (B)-(F) is the $1-5$ amino acids of inclusion bodies $\mathrm{N}$-terminus. Table S1. Primers used in this study.

\section{Abbreviations}

AmyS: a-amylase; AmySA: a-amylase mutant K82E/S405R; GRAS: generally recognized as safe; TF: trigger factor; DCW: dry cell weight; DNS: 3,5-dinitrosalicylic acid; SDS-PAGE: sodium dodecyl sulfate-polyacrylamide gel electrophoresis.

\section{Authors' contributions}

DBY designed and carried out the experiments, drafted the manuscript, $\mathrm{NL}$ carried out the experiments, JW and LQS supervised the project and revised the manuscript. All authors read and approved the final manuscript.

\section{Author details}

'State Key Laboratory of Food Science and Technology, Jiangnan University, 1800 Lihu Avenue, Wuxi 214122, Jiangsu, China. ${ }^{2}$ School of Biotechnology and Key Laboratory of Industrial Biotechnology Ministry of Education,
Jiangnan University, 1800 Lihu Avenue, Wuxi 214122, China. ${ }^{3}$ International Joint Laboratory on Food Safety, Jiangnan University, 1800 Lihu Avenue, Wuxi 214122, China.

\section{Acknowledgements}

Not applicable.

\section{Competing interests}

The authors declare that they have no competing interests.

\section{Availability of data and materials}

All data generated or analysed during this study are included in this published article and its additional files.

\section{Consent for publication}

Not applicable.

\section{Ethics approval and consent to participate}

Not applicable.

\section{Funding}

This work was supported by grants from the National Science Fund for the National Natural Science Foundation of China (31730067), the Natural Science Foundation of Jiangsu Province (BK20180082), the National Science Fund for Distinguished Young Scholars (31425020), the national first-class discipline programme of Light Industry Technology and Engineering (LITE2018-03), and the 111 Project (No. 111-2-06).

\section{Publisher's Note}

Springer Nature remains neutral with regard to jurisdictional claims in published maps and institutional affiliations. 
Received: 21 November 2018 Accepted: 3 April 2019

Published online: 11 April 2019

\section{References}

1. Gupta R, Gigras P, Mohapatra H, Goswami VK, Chauhan B. Microbial alpha-amylases: a biotechnological perspective. Process Biochem. 2003:38:1599-616.

2. Hussain I, Siddique F, Mahmood MS, Ahmed SI. A review of the microbiological aspect of alpha-amylase production. Int J Agric Biol. 2013;15:1029-34

3. Gopinath SCB, Anbu P, Arshad MKM, Lakshmipriya T, Voon CH, Hashim U, Chinni SV. Biotechnological processes in microbial amylase produc tion. Biomed Res Int. 2017. https://doi.org/10.1155/2017/1272193.

4. Li Z, Duan X, Wu J. Improving the thermostability and enhancing the $\mathrm{Ca} 2+$ binding of the maltohexaose-forming a-amylase from Bacillus stearothermophilus. J Biotechnol. 2016:222:65-72.

5. Kiribayeva A, Ramanculov E, Khassenov B. Constitutive expression of thermostable a-amylase from Bacillus licheniformis in Pichia pastoris. J Biotechnol. 2017;256:S64

6. Chen J, Fu G, Gai Y, Zheng P, Zhang D, Wen J. Improving the thermostability and enhancing the $\mathrm{Ca}^{2+}$ binding of the maltohexaoseforming a-amylase from Bacillus stearothermophilus. Microb Cell Fact. 2015;14:92

7. Heng C, Chen Z, Du L, Lu F. Expression and secretion of an acid-stable a-amylase gene in Bacillus subtilis by SacB promoter and signal peptide. Biotechnol Lett. 2005;27:1731-7.

8. Fu G, Liu J, Li J, Zhu B, Zhang D. Systematic screening of optimal signal peptides for secretory production of heterologous proteins in Bacillus subtilis. J Agric Food Chem. 2018:66:13141-51.

9. Vitikainen M, Pummi T, Airaksinen U, Wahlström E, Wu H, Sarvas M, Kontinen VP. Quantitation of the capacity of the secretion apparatus and requirement for Prs $\mathrm{A}$ in growth and secretion of a-amylase in Bacillus subtilis. J Bacteriol. 2001;183:1881-90.

10. Ying Q, Zhang C, Guo F, Wang S, Bie X, Lu F, Lu Z. Secreted expression of a hyperthermophilic a-amylase gene from Thermococcus sp. HJ21 in Bacillus subtilis. J Mol Microbiol Biotechnol. 2012;22:392-8.

11. Natale P, Brüser T, Driessen AJ. Sec-and Tat-mediated protein secretion across the bacterial cytoplasmic membrane-distinct translocases and mechanisms. Biochim Biophys Acta (BBA) Biomembr. 2008;1778:1735-56.

12. Brockmeier U, Caspers M, Freudl R, Jockwer A, Noll T, Eggert T. Systematic screening of all signal peptides from Bacillus subtilis: a powerful strategy in optimizing heterologous protein secretion in Gram-positive bacteria. J Mol Biol. 2006:362:393-402.

13. Zhang W, Yang M, Yang Y, Zhan J, Zhou Y, Zhao X. Optimal secretion of alkali-tolerant xylanase in Bacillus subtilis by signal peptide screening. Appl Microbiol Biotechnol. 2016;100:8745-56.

14. Tsuji S, Tanaka K, Takenaka S, Yoshida KI. Enhanced secretion of natto phytase by Bacillus subtilis. Biosci Biotechnol Biochem. 2015;79:1906-14.

15. Tjalsma H, Bolhuis A, Jongbloed JD, Bron S, van Dijl JM. Signal peptidedependent protein transport in Bacillus subtilis: a genome-based survey of the secretome. Microbiol Mol Biol Rev. 2000;64:515-47.

16. Ben A, Mezghani M, Bejar S. A thermostable a-amylase producing maltohexaose from a new isolated Bacillus sp. US100: study of activity and molecular cloning of the corresponding gene. Enzyme Microb Technol. 1999:24:584

17. Aiba S, Kitai K, Imanaka T. Cloning and expression of thermostable alpha-amylase gene from Bacillus stearothermophilus in Bacillus stearothermophilus and Bacillus subtilis. Appl Environ Microbiol. 1983;46:1059-65.

18. Davis PE, Cohen DL, Whitaker A. The production of a-amylase in batch and chemostat culture by Bacillus stearothermophilus. Antonie Van Leeuwenhoek. 1980:46:391-8.

19. Zhang K, Su L, Duan X, Liu L, Wu J. High-level extracellular protein production in Bacillus subtilis using an optimized dual-promoter expression system. Microb Cell Fact. 2017;16:32.
20. Anagnostopoulos C, Spizizen J. Requirements for transformation in Bacillus subtilis. J Bacteriol. 1961;81:741-6.

21. Zhou Y, Zhang X, Ebright RH. Random mutagenesis of gene-sized DNA molecules by use of PCR with Taq DNA polymerase. Nucleic Acids Res. 1991;19:6052.

22. Miller GL. Use of dinitrosalicylic acid reagent for determination of reducing sugar. Anal Chem. 1959:31:426-8.

23. Zhang K, Su L, Wu J. Enhanced extracellular pullulanase production in Bacillus subtilis using protease-deficient strains and optimal feeding. Appl Microbiol Biotechnol. 2018;102:5089-103.

24. Yoshihisa T, Ito K. Pro-OmpA derivatives with a His Tag in their N-terminal translocation initiation domains are arrested by $\mathrm{Ni}$ at an early post-targeting stage of translocation. J Biol Chem. 1996;271:9429-36.

25. Kakeshtia H, Kageyama Y, Ara K, Ozaki K, Nakamura K. Enhanced extracellular production of heterologous proteins in Bacillus subtilis by deleting the C-terminal region of the SecA secretory machinery. Mol Biotechnol. 2010;46:250-7.

26. Park S, Schumann W. Optimization of the secretion pathway for heterologous proteins in Bacillus subtilis. Biotechnol Bioprocess Eng. 2015;20:623-33.

27. Mulder KC, Bandola J, Schumann W. Construction of an artificial secYEG operon allowing high level secretion of a-amylase. Protein Expr Purif. 2013;89:92-6.

28. Freudl R. Signal peptides for recombinant protein secretion in bacterial expression systems. Microb Cell Fact. 2018;17:52

29. Fu LL, Xu ZR, Li WF, Shuai JB, Lu P, Hu CX. Protein secretion pathways in Bacillus subtilis: implication for optimization of heterologous protein secretion. Biotechnol Adv. 2007;25:1-12.

30. Caspers M, Brockmeier U, Degering C, Eggert T, Freudl R. Improvement of Sec-dependent secretion of a heterologous model protein in Bacillus subtilis by saturation mutagenesis of the N-domain of the AmyE signal peptide. Appl Microbiol Biotechnol. 2010;86:1877-85.

31. Sarvas M, Harwood CR, Bron S, van Dijl JM. Post-translocational folding of secretory proteins in Gram-positive bacteria. Biochim Biophys Acta Mol Cell Res. 2004;1694:311-27.

32. Kontinen V, Saris P, Sarvas M. A gene (prsA) of Bacillus subtilis involved in a novel, late stage of protein export. Mol Microbiol. 1991;5:1273-83.

33. Bolhuis A, Tjalsma H, Smith HE, de Jong A, Meima R, Venema G, Bron $S$, van Dijl JM. Evaluation of bottlenecks in the late stages of protein secretion in Bacillus subtilis. Appl Environ Microbiol. 1999;65:2934-41.

34. Yan S, Wu G. Bottleneck in secretion of a-amylase in Bacillus subtilis. Microb Cell Fact. 2017:16:124.

35. Darmon E, Noone D, Masson A, Bron S, Kuipers OP, Devine KM, van Dijl JM. A novel class of heat and secretion stress-responsive genes is controlled by the autoregulated CssRS two-component system of Bacillus subtilis. J Bacteriol. 2002;184:5661-71.

36. Lee SC, Olins PO. Effect of overproduction of heat-shock chaperones GroESL and DnaK on human procollagenase production in Escherichia coli. J Biol Chem. 1992;267:2849-52.

37. Blum P, Ory J, Bauernfeind J, Krska J. Physiological consequences of DnaK and DnaJ overproduction in Escherichia coli. J Bacteriol. 1992;174:7436-44

38. Mogk A, Homuth G, Scholz C, Kim L, Schmid FX, Schumann W. The GroE chaperonin machine is a major modulator of the CIRCE heat shock regulon of Bacillus subtilis. EMBO J. 1997;16:4579-90.

39. Yuan G, Wong S-L. Isolation and characterization of Bacillus subtilis groE regulatory mutants: evidence for orf39 in the dnaK operon as a repressor gene in regulating the expression of both groE and dnaK. J Bacteriol. 1995;177:6462-8.

40. Wu SC, Ye RQ, Wu XC, Ng SC, Wong SL. Enhanced secretory production of a single-chain antibody fragment from Bacillus subtilis by coproduction of molecular chaperones. J Bacteriol. 1998:180:2830-5.

41. Li W, Zhou X, Lu P. Bottlenecks in the expression and secretion of heterologous proteins in Bacillus subtilis. Res Microbiol. 2004;155:605-10.

42. Gasteiger E, Hoogland C, Gattiker A, Wilkins MR, Appel RD, Bairoch A. Protein identification and analysis tools on the ExPASy server. In: Walker JM, editor. The proteomics protocols handbook. Berlin: Springer; 2005. p. 571-607.

43. Whitford D. Proteins structure and function. New York: Wiley; 2013. 